\title{
RECURSOS NATURALES: UNA ALTERNATIVA UTILIZADA COMO COMPLEMENTO TERAPÉUTICO POR LAS PERSONAS QUE VIVEN CON EL VIRUS / SÍNDROME DE INMUNODEFICIENCIA ADQUIRIDA (PVV). TAMPICO TAMAULIPAS. MÉXICO
}

\author{
$M^{a}$. del Socorro Piñones Martínez, José Siles González, Isabel Lagarriga Attias
}

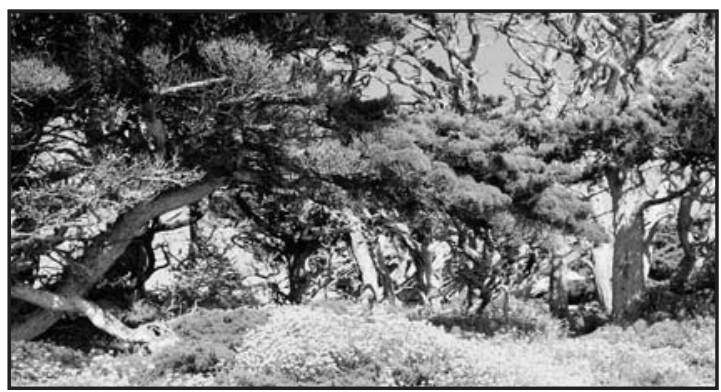

NATURAL RESOURCES: AN ALTERNATIVE USED AS A COMPLEMENTARY THERAPY BY PEOPLE WHO LIVE WITH VIRUS/IMMUNE-DEFICIENCY ACQUIRED SYNDROME. TAMPICO TAMAULIPAS. MÉXICO

\section{SUMMARY}

Aims: Were centred in understanding and explaining the meaning of natural resources for those people living with AIDS, from the perspective of anthropology of care, at the same time to determine which are those resources and their effectiveness from the users' perspective and to know how they apprehend those natural resources, who recommend them, as well as their influence in persevering with traditional medicine. Also to request opinions about such natural resources among their own traditional medical doctors.

Methodology: A qualitative descriptive study was performed by means of action investigation type based on an ethnographic method. The sample was constituted by 1263 individuals living with the virus or AIDS, registered cases within the Jurisdicción Sanitaria II in Tampico (Mexico) (CONASIDA -2002), from whom 180 form a self- aid group fully coordinated with the Frente Nacional de Personas Afectadas de Virus de SIDA. (FRENPAVIH-2004). 14 individuals were selected as key informants in a convenient sample. Doctors opinions were considered due to their paramount knowledge with respect to the matter, their selection done at random but for their premise of being directly involved in AIDS patients.

Results: 39 different types of vegetables (medical plants, fruits and greens). No specifically taken into consideration for the treatment were some mineral or animal resources. The AIDS people declare having used some green resources, as from their personal point of view they have experienced an improvement in their health, they feel better . They buy them locally (natural resources shops, herbal shops or are cultivated in their own gardens). They have been recommended by people of their own environment, their social group, their family or got them from the self-aid group where they belong to.

Doctors participant in the study express that natural resources as an alternative or complement to traditional medical treatment to AIDS are not scientific but they confess not to be familiarized with those medical plants o alternative medicine.

Conclusions: According to testimonials the conclusion is that there is evidence that within these type of groups their common habits and health beliefs are present in their lives thus the use of natural resources in AIDS patients go parallel to the traditional medical treatments and together with their own values and way of life, social environment where they belong to what allows them to have their personal cosmos-vision idea. 
Leininger and his model of trans-cultural nursing suggests different cultures are to be considered with their own convictions of health and illness, what would allow a specific traditional sanitary care as well, because patterns and life styles have an important influence in people's decisions. He also takes into account Emicos' point of view, the essence of human being and he suggests as well that combining them with traditional professional knowledge would help to adopt actions and take decisions coherent with cosmos-vision.

Key-words: traditional Medicine, Anthropology, natural resources, VIH, SIDA

\section{RECURSOS NATURAIS: UMA ALTERNATI- VA UTILIZADA COMO COMPLEMENTO TERAPÊUTICO PELAS PESSOAS QUE VIVEM COM O VÍRUS DA SÍNDROME DE IMUNODEFICIÊNCIA ADQUIRIDA (AIDS). TAMPICO TAMAULIPAS. MÉXICO}

\section{RESUMO}

Objetivos: os objetivos estão voltados para compreender e explicar qual o significado dos recursos naturais para as pessoas que vivem com HIV/AIDS, na perspectiva da antropologia dos cuidados, da mesma maneira, objetiva-se determinar quais são esses recursos e a efetividade, na perspectiva dos usuários, e conhecer como adquirem os recursos naturais, quem os recomenda, bem como a influência das persistência da medicina tradicional e do entorno social no uso deles; além de indagar a opinião de médicos lidam com essa questão.

Metodologia: o estudo foi do tipo qualitativo, descritivo, por meio da investigação-ação, baseado no método etnográfico. O universo do estudo foi constituído por 1263 pessoas que vivem com o vírus da Síndrome de Imunodeficiência Adquirida ((PVVS o PVV)), casos registrados na Jurisdição Sanitária II em Tampico Tamaulipas, México (CONASIDA-2002), das quais 180 integram o grupo de auto ajuda, o qual encontra apoio na Frente Nacional de Pessoas Afetadas pelo Vírus da AIDS. (FRENPAVIH-2004). Foram selecionados
14 colaboradores, a partir de uma amostra de conveniência. As opiniões dos médicos foram consideradas devido ao primordial de seus discernimentos com relação ao tema, e esses foram selecionados aleatoriamente, com o antecedente de haver atendido a PVVS.

Resultados: Foram identificados 39 diferentes recursos vegetais (plantas medicinais, frutas e verduras); entretanto, não foram mencionados, em específico, recursos minerais ou animais para o tratamento. As PVVS alegam ter utilizado os recursos vegetais, argumentando buscá-los porque se sentem bem, quando os consomem, adquirindo-os na localidade (lojas de ervas, lojas de produtos naturais, ou em seus próprios jardins), recomendandoos a pessoas do grupo social (familiares) e do grupo de auto ajuda, ao qual pertencem. Os médicos participantes emitiram suas opiniões, considerando que o uso dos recursos naturais como terapia alternativa ou complementar no caso do HIV, não é científico e com suas respostas concretas referem desconhecer de plantas medicinais ou medicina alternativa.

Conclusões: Com base em testemunhos, concluise que é evidente que nesse grupo, a cultura está presente em seus costumes e crenças de saúde, que determinam o uso dos recursos naturais no HIV/AIDS, já que neles persiste a cultura da Medicina Tradicional derivada de seus valores e a forma de vida do entorno social ao qual pertencem, que lhes possibilita ter sua própria visão de mundo. Leininger, com seu modelo de enfermagem transcultural, sugere-nos que devem ser consideradas as diferentes culturas acerca da visão de mundo, da saúde e enfermidade, o que permite uma prática da atenção à saúde específica, já que os padrões e estilos de vida têm influência nas decisões das pessoas. Ademais, considera de grande importância os pontos de vista Emicos, a essência interna do ser, e sugere que ao combinar tudo isso com o conhecimento profissional, podem ser adotadas ações e decisões coerentes com a cosmovisão.

Palavras-chave: Medicina tradicional; Antropologia; Recursos naturais; HIV; AIDS. 


\section{RESUMEN \\ OBJETIVOS}

Los objetivos se centraron en comprender y explicar cuál es significado que de los recursos naturales para las personas que viven con el VIH/SIDA (PVVS o PVV), desde la perspectiva de la antropología de los cuidados, de la misma forma determinar cuáles son estos recursos y la efectividad desde la perspectiva los usuarios y conocer cómo adquieren los recursos naturales, quien los recomienda, así como la influencia de la persistencia de la medicina tradicional del entorno social en el uso de estos e Indagar la opinión de médicos tratantes, respecto al tema.

\section{METODOLOGÍA}

El estudio fue de tipo cualitativo descriptivo a través de la investigación acción, basado en un método etnográfico, El universo estuvo constituido por 1263 personas que viven con el virus o el síndrome de inmunodeficiencia adquirida (PVVS o PVV), casos registrados en Jurisdicción Sanitaria II en Tampico Tamaulipas, México (CONASIDA2002), de las cuales 180 integran el grupo de autoapoyo coordinándose con el Frente Nacional de Personas Afectadas por el Virus del Sida. (FRENPAVIH-2004). Seleccionando a 14 informantes clave en un muestreo por conveniencia. Las opiniones de los médicos, fueron consideradas debido a lo primordial de sus discernimientos con respecto al tema, estos fueron seleccionados al azar, con el antecedente de haber atendido a PVVS.

\section{RESULTADOS}

Se lograron identificar 39 diferentes recursos vegetales (plantas medicinales, frutos y verduras) no fueron mencionados en específico algunos recursos minerales o animales para el tratamiento. Las PVVS aducen haber utilizado los recursos vegetales, argumentando recurrir a ellos porque desde su perspectiva se sienten bien cuando los consumen, los adquieren en la localidad (hierbearías, tiendas naturistas, sus propios jardines) y se los recomiendan personas del grupo social- familiar y del grupo de autoapoyo al cual pertenecen. Los médicos participantes emitieron sus opiniones en donde consideran que el uso de los recursos naturales como alternativa o complemento de trata- miento en el VIH, no es científico y con sus respuestas concretas refieren desconocer de plantas medicinales o medicina alternativa.

\section{CONCLUSIONES}

Con base a testimonios se concluye que es evidente que en este grupo la cultura está presente en sus costumbres y creencias de salud, que determinan el uso de los recursos naturales en el VIH/SIDA, ya que en ellos persiste la cultura de la Medicina Tradicional derivada de sus valores y la forma de vida del entorno social al que pertenecen, que les permite tener su propia cosmovisión.

Leininger con su modelo de enfermería transcultural, nos sugiere que se deben considerar las diferentes culturas respecto a las convicciones de la salud y la enfermedad, que permita una práctica de la atención sanitaria específica, ya que los patrones y estilos de vida tienen influencia en las decisiones de las personas, además considera de gran importancia los punto de vista Emicos, la esencia interna del ser, y sugiere que al combinar estos con el conocimiento profesional, se podrán adoptar acciones y decisiones coherentes a la cosmovisión.

Palabras clave: medicina tradicional, antropología, Recursos naturales, VIH, SIDA

\section{INTRODUCCIÓN}

Una de las preocupaciones más grandes que ha tenido el hombre a través de la historia ha sido como resolver sus problemas de salud, encontrando la respuesta en el mundo que le rodea como son los recursos naturales y su estilo de vida, por tal motivo en 1976 en la 29a Asamblea Mundial de la Salud, un grupo de países se presentaron por primera vez a la Organización Mundial de la Salud (OMS) para pedir, se tomara en cuenta a la Medicina tradicional, parte esencial de la cultura de salud de los pueblos.

En 1977 la Organización Mundial de la Salud (OMS) realiza la conferencia de Alma Ata, cuyo lema fue "salud para todos en el año 2000" del la cual surge una revaloración de la Medicina Tradicional. Considerándola en 1978 como: "la suma de todos los conocimientos teorías y prácti- 


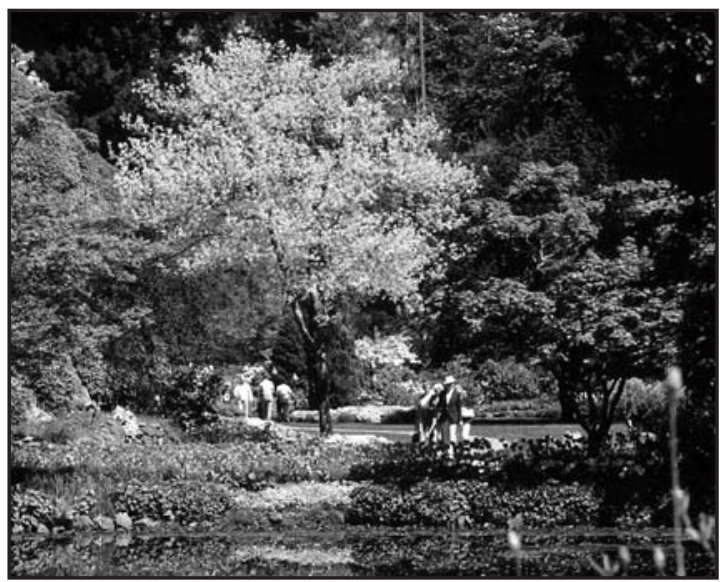

cas explicables o no, utilizados para diagnóstico, prevención y supresión de trastornos físicos, mentales o sociales, basados exclusivamente en la experiencia y la observación, trasmitidos verbalmente o por escrito de una generación a otra".

En esta misma reunión queda establecido que para llevar a cabo la política de la "Salud para todos en el año 2000" era necesaria una estrategia específica, llamada "Atención primaria de salud", dicha estrategia sugiere a los países en vías de desarrollo el uso de los recursos disponibles de la comunidad para el logro de sus objetivos en los programas de salud. Para lograr dichos objetivos es de gran importancia el uso la medicina tradicional, que permite dar respuesta a las necesidades de salud que no pueden ser cubiertas con los servicios oficiales de salud y que son de acuerdo a las culturas de los pueblos.

Oficialmente la OMS con la declaración surgida en Alma Atta en 1979, reafirma la invitación a los países miembros a que aprovecharan las experiencias y conocimientos de la población sobre la medicina tradicional y que lograran la participación activa de la población, aprovechando sus conocimientos en esta medicina, considerando sus necesidades, recursos locales y las características sociales como culturales.

Piñones (1992) considera que, el que el uso de la medicina tradicional actualmente este resurgiendo paralela al uso de la medicina científica puede estar ligada a las condiciones sociales y económicas por las que se cursa, ya que la cobertura de los servicios de salud en México, es limitado e inaccesible principalmente en las regiones rurales margi- nadas, por lo que la medicina tradicional con el uso de la herbolaria presenta una respuesta social que la comunidad hace ante la realidad de su problemática de salud.

La OMS en 1984 confirma este hecho señalado que entre el 70 y $90 \%$ de las enfermedades no son tratadas por los sistemas convencionales de salud. Es por ello que en mayo 2002 en Ginebra se define a "la medicina tradicional como prácticas, enfoques, conocimientos y creencias sanitarias diversas que incorporan medicinas basadas en plantas, animales y/o minerales, terapias espirituales, técnicas manuales y ejercicios aplicados de forma individual o en combinación para mantener el bienestar, además de tratar, diagnosticar y prevenir las enfermedades".

En la reunión celebrada en Kampala en junio del 2000, y patrocinada por el ONUSIDA (Programa de las Naciones Unidas contra el VIH/SIDA) se acordó que la medicina tradicional está en un sentido real llevando la carga de la epidemia del SIDA en África, y consideran que los Ministerios de Salud y las agencias internacionales han pasado por alto esta tendencia,

Así mismo en estudio reciente ha demostrado que el $78 \%$ de los pacientes que padecen VIH/SIDA en EE UU utilizan alguna forma de Medicina Tradicional o complementaria alternativa, para obtener una cura sintomática y tratar las infecciones oportunistas. También señala que en los países en vías de desarrollo hasta el $80 \%$ de su población utiliza la herbolaria o alguna otra alternativa (OMS- 2002 al 2005).

Investigadores como Leininger (en Marriner p.429 1999) refiere que se deben considerar las diferentes culturas y subcultura del mundo, desde el punto de vista de sus valores asistenciales, valores culturales, formas de vida, lenguaje, de la expresión y convicciones sobre la salud y la enfermedad y de los modelos de conducta, siempre con el propósito de desarrollar una base de conocimientos científicos y humanísticos que permitan una práctica de la atención sanitaria específica de la cultura y / o universal.

De tal manera que cada una de las personas que viven con el VIH /SIDA al igual que cualquier otro individuo que ve mermada su salud, recurre al recurso terapéutico que considera resolverá el problema que le aqueja y esto puede ser influenciado 
por su cosmovisión. Las siglas utilizadas para identificar esta enfermedad son VIH (Virus de inmunodeficiencia Humana) virus que causa el SIDA (AIDS en inglés) síndrome de inmunodeficiencia adquirida. El primer caso diagnosticado en América fue en Estados Unidos en la Florida en 1980 y en los Ángeles California en 1981.

En México 1983 el primer caso ingresa al Hospital de zona No. 1 del Instituto Mexicano del Seguro Social de la Ciudad de México. En la actualidad no se cuenta aún con el tratamiento curativo para las PVVS (Nieto, C. L.1996), éstos han recurrido a las medicinas alternativas o complementarias según su creencias, su cultura y su nivel socioeconómico y esto puede estar condicionado por poseer un concepto de salud - enfermedad natural o sobrenatural de acuerdo a su cosmovisión, donde consideran el bien y el mal y que la enfermedad puede ser por causa científicamente comprobada o por fuerzas inanimadas, deidades enojadas por comportamientos inmorales. (Piñones, 1992).

\section{OBJETIVOS}

Los objetivos del presente trabajo fueron comprender y explicar el significado que tienen los recursos naturales para las personas que viven con el VIH/SIDA (PVVS o PVV), desde la perspectiva de la antropología de los cuidados, asi mismo determinar cuáles son estos recursos y la efectividad del tratamiento alternativo o complementario desde la perspectiva los usuarios. Además se consideró conocer cómo adquieren los recursos naturales, quien los recomienda y del mismo modo identificar la influencia de la persistencia de la medicina tradicional del entorno social en el uso de estos e Indagar la opinión de médicos tratantes, respecto al tema.

\section{ESTADO DE LA CUESTIÓN}

Leininger considera que la diversidad y universalidad de los cuidados culturales tienen una gran importancia y que al interactuar con las personas de diferentes culturas se puede obtener información que permita al profesional de salud orientar la atención y los cuidados de enfermería adecuados a la cultura que cada individuo necesita. En uno de sus supuestos señala que enfermería es un fenómeno transcultural, en donde los enfermeros/as inte- raccionan con los pacientes y los grupos, y se requiere que los enfermeros/as identifiquen $\mathrm{y}$ empleen datos culturales enfermeros/as - paciente y sistema, para que los cuidados se deriven en gran parte de la cultura de cada individuo. (Marriner, 1994).

De la misma forma Piñones en 1992, concluye en su estudio en una comunidad urbano marginada de Nuevo León, México, que independientemente de que la comunidad cuente con servicios oficiales de salud, continúa con el uso de la medicina tradicional, siendo esta la primera alternativa de solución que eligen al ver afectada su salud con los primeros síntomas de cualquier tipo de enfermedad.

Asi mismo en Hermosillo Sonora en 1996, se realizó un estudio en la unidad de medicina familiar No. 37, en una comunidad urbana, sobre la aceptación y uso de la herbolaria en medicina familiar, encontrándose que el $92 \%$ de los usuarios aceptan utilizar plantas medicinales, de igual forma pero en un $100 \%$ lo hace el personal de salud, el $83 \%$ de los médicos refiere aceptarla y un $75 \%$ contesto que la utiliza.(Taddei y Santillana 1999).

En el año de 1993 se llevó a cabo un encuentro en la Cd. De Chihuahua, del 7 al 11 de septiembre, convocada por el Instituto Nacional de Antropología e Historia (INAH), con la participación y apoyo del instituto Nacional Indigenista (INI), y la Universidad Autónoma de Chihuahua entre otras, dentro de la temática principal se abordaron temas como: Medicina tradicional e historia, medicina tradicional y el uso de los recurso naturales, enfermedades tradicionales en la conceptualización regional entre otras.

En el caso de Lagarriga Attias en su conferencia las enfermedades tradicionales regionales, hace hincapié, con respecto a que en México la concepción de las enfermedades tradicionales parten de principios universales y que han perdurado con el paso de los siglos (Lagarriga en Ortiz,1999).

Oramas y Rodríguez (1999, p.39-46) refieren que en Australia el $80 \%$ de las personas infectadas por el VIH han recurrido a algunas de las formas de tratamiento alternativo, en donde incluyen enfoques nutricionales, acupuntura, homeopatía, ejercicios, dieta macrobiótica, meditación, calor, hielo, música y productos mentolados, además de emplear la aromaterapia con aceites esenciales y extrac- 
tos de flores y hierbas aromáticas incluyendo en algunos casos, minerales aromáticos; también practican el reiki, que es una forma de masaje que se basa en la filosofía sobre la energía natural, la homeopatía y el gigong que emplea actividad física y meditación.

Utilizan también vitaminas extraídas de plantas medicinales como el ajo y la hipericina (un extracto de la planta Mosto de San Juan); otros tratamientos utilizando los tejidos de algunos mamíferos y en el cartílago de tiburón; el Lentinus edodes mycelia, un producto obtenido de los hongos Shiitaki, hacen una combinación con todo ello para utilizarla como alternativo complementario en el VIH/SIDA. Argumentan que los productos naturales empleados en el objetivo de mejorar los males que aquejan al hombre le han acompañado en el transcurso de los siglos coincidiendo en esto ultimo con Lagarriga en 1975, 1999 y Piñones en1992.

En la $56^{\mathrm{a}}$ asamblea mundial de salud el 31 de marzo del 2003, se hace mención de la importancia del uso de la medicina tradicional para tratar o prevenir dolencias y enfermedades crónicas y para mejorar la calidad de vida, incluyendo para tratar y cuidar pacientes con enfermedades potencialmente mortales como el paludismo y el SIDA. Señala que hasta el 75\% de las personas con VIH/SIDA utilizaban la medicina tradicional sola o combinada con otras medicinas, para diversos síntomas y afecciones.

De la misma forma en el Documento de Estrategia de la OMS sobre medicina tradicional 2002-2005 menciona: "En una reunión en Kampala celebrada en junio del 2000, y patrocinando por el ONUSIDA se acordó que la medicina tradicional está en un sentido real llevando la carga de la atención clínica de la epidemia del SIDA en África. Los ministerios y las agencias internacionales han pasado por alto esta tendencia”. ONUSIDA es partidario de colaborar con los practicantes de la medicina tradicional en la prevención del SIDA y la OMS dice que la medicina tradicional está incrustada en un amplio sistema de ceencias y sigue siendo una parte integral e importante en la vida de las personas en el mundo.

También refieren que La atención en África Subsahariana, la mayoría de los africanos que viven con VIH/SIDA utilizan medicinas tradicionales con base de hierbas para obtener una cura sintomática y tratar las infecciones oportunistas. Además señala que "un estudio reciente ha demostrado que el $78 \%$ de las personas que padecen VIH/SIDA en EEUU utiliza alguna forma de medicina tradicional". Considera que muchas poblaciones de países en vías de desarrollo utilizan la medicina tradicional, y que las poblaciones de países desarrollados por lo menos una vez la han utilizado, considera que es necesario que la medicina tradicional esté disponible mucho más en los países más pobre.

Además considerando la posibilidad de aumentar la cooperación entre los proveedores de la medicina tradicional y los trabajadores sanitarios comunitarios, enfatizando los problemas sanitarios prioritarios como el VIH/SIDA. Sin dejar a un lado lo relevante de tomar en cuanta que también existen riesgos de interacciones medicamentosas. Ha sido demostrado que algunos fitofármacos modifican las concentraciones plasmáticas y el efecto de drogas antirretrovirales por ejemplo la Hypericum Perforatum disminuye las concentraciones de Indinavir entre un $20 \%$ y $50 \%$; Lentinus edodes incrementa la acción de las drogas retrovirales. (OMS 2000-2005).

Rachel King colaborador del programa conjunto de las naciones unidas sobre el VIH/SIDA (2002), considera que a medida que la pandemia de VIH/SIDA continua devastando al mundo es necesario buscar, examinar, adaptar y adoptar estrategias para combatirla. Refiere que las técnicas de los curanderos tradicionales están entre las estrategias que deben ser investigadas más a fondo para ver la posibilidad de adoptarlas.

El uso de las plantas medicinales se ha extendido por todo el mundo, generando en los investigadores de salud inquietud por conocer mas a fondo la evidencia científica de su efectividad en el VIH/SIDA, muestra de ello es dentro de la homeopatía la investigación realizada por Moral Parras, medico homeópata, quien llevó a cabo un estudio y seguimiento clínico y analítico de enfermos de VIH a los que se les proporcionó un preparado nutricional junto con tratamiento homeopático. Sus conclusiones fueron que se puede inducir a una recuperación con el complemento de principios 
nutricionales y la homeopatía específica (medicina-naturista.net).

También existen diversas fuentes de información en Internet como el de medlineplus, que brinda información sobre hierbas medicinales suplementos, terapias complementarias y alternativas, también la página de todosida-hierbas entre otras ,donde se puede encontrar una gran variedad de plantas medicinales, esta es una más de la evidencias de que el uso de los recursos naturales y la medicina tradicional es vigente y tangible, cómo también lo refiere Piñones (1992) en su estudio de persistencia de la medicina tradicional en una comunidad urbana.

Es motivarte encontrar trabajos que evidencian el interés por enfermeros(as) por conocer como funciona la medicina tradicional, como es el caso de Quédrago (2003), quien en su estudio “experiencias de un enfermero con la medicina tradicional" señala que los curanderos pueden coordinarse y prestar servicio a la administración y a la medicina moderna, orientando a la ejecución de los programas (index-Enfermeria), coincidiendo con lo señalado por Leininger cundo afirma que la diversidad de los cuidados culturales, se basa en la convicción de que las personas de culturas diferentes pueden ofrecer información y orientar para recibir la clase de cuidados que desean o necesitan de los demás.

\section{El estudio de las plantas medicinales en México:}

En todo el mundo existen diversas instituciones académicas y de investigación que se dedican a realizar estudios científicos sobre plantas medicinales, en México sobresalen estudios realizados en la Universidad Nacional Autónoma de México, el Instituto politécnico Nacional, La Universidad Autónoma de Chapingo, la Universidad Autónoma metropolitana, el Instituto Nacional de la Nutrición y el Instituto Mexicano del Seguro Social (IMSS) quien actualmente cuenta con una coordinación de investigación en salud,área que realiza investigaciones sobre las propiedades medicinales de las plantas a cargo del Dr. Xavier Lozoya, en la división de investigación biomédica, que lleva el herbario medicinal de Seguro Social.

El IMSS tiene una amplia trayectoria en la investigación de la medicina tradicional, tal experiencia data de 1975 donde en sus inicios se dieron a la tares de identificar y capacitar a parteras empíricas y a la búsqueda e identificación de los prestadores tradicionales de salud en las áreas marginadas a través de los IMSS- COPLAMAR actualmente llamados IMSS-SOLIDARIDAD y coordinados por el entonces llamado IMEPLAM dirigido por dos distinguidos investigadores el Dr. Lozoya y el Dr Zolla. Y en el ya desaparecido Instituto Nacional Indigenista (INI)

Existen también algunas fundaciones que reportan sus experiencias con el uso de medicinas complementarias o alternativas, tal es el caso de la fundación anti-SIDA de San Francisco que a través de un boletín en octubre de 1997, menciona lo siguiente, "Desde el principio de la epidemia del SIDA, las personas VIH positivas han empleado diferentes componentes de la medicina complementaria alternativa como lo es la medicina China, que ha resultado consistente como una de las modalidades alternativas más populares" (Jeslie, H. 1997).

La UNESCO promueve tomar en cuenta las culturas de las poblaciones de que se trate por los programas de lucha contra el VIH/SIDA, Con un enfoque socioantropológico para combatir y prevenir la enfermedad en función de los recursos culturales de las poblaciones afectadas, considerando la gran importancia las diferentes concepciones del cuerpo y de la enfermedad, las creencias correspondientes, las practicas tradicionales de salud y el uso de las plantas medicinales. (UNESCO.org, 2004)

Actualmente el maestro Erick Estrada Lugo con una vasta experiencia en la etnobotánica es el encargado del departamento de atención comunitaria en la Universidad Autónoma de Chapingo, desarrolla el programa de servicios tradicionales de salud con la utilización de recursos naturales como tratamiento en diversos padecimientos. (http://www.jornada.unam.mx/1998/06/29/cien panorama.html 2005).

Cabe señalar que durante la búsqueda de bibliografía, no fue posible encontrar suficientes fuentes en relación al tema, son pocas las aportadas por Enfermeria, en su mayoría surgen de estudios antropológicos, Médicos y otros de la Antropología Medica, así como de la etnobotánica, se encontraron una gran variedad de artículos, que al revisar sus fuentes de información y contenido no resultaron significativos pero si poco confiables. 
Por lo anterior es importante que el personal de enfermería haga observaciones sistemáticas al respecto, tomando en cuenta la cultura del cuidado basado en la enfermería transcultural considerando y respetando los patrones y estilos de vida de las PVVS y su decisión de utilizar recursos naturales como tratamiento alternativo o complementario para resolver sus problemas de salud y mejorar su calidad de vida, por lo que las enfermeras/os no pueden permanecer indiferentes ante esta realidad.

\section{METODOLOGÍA}

Estudio de tipo cualitativo descriptivo, a través de la investigación acción participativa, aplicando el método etnográfico, para alcanzar los objetivos de estudio y peculiaridades específicas del modelo teórico. El universo fue de 1263 PVVS, casos registrados en Tampico Tamaulipas para la Jurisdicción Sanitaria II (CONASIDA-2002), de las cuales 180 integran el grupo de autoapoyo del Frente Nacional de Personas Afectadas por el Virus del Sida (FRENPAVIH-2004). El muestreo fue por conveniencia, considerando además la opinión de los médicos tratantes, debido a lo primordial de sus discernimientos con respecto al tema, seleccionados al azar, con el antecedente de haber atendido a PVVS.

Con la finalidad de obtener una visión total de los sujetos, se consideró realizar historias de vida, con el fin de identificar a profundidad como se fue dando el proceso de la enfermedad y conocer a detalle aspectos relevantes de su entorno social. Se realiza observación participante registrándose notas en diario de campo sobre el entorno y actitud ante la enfermedad, así mismo se realizan entrevistas incidentales. Se realizan grabaciones en cinta y video, además de fotografía, con previo consentimiento.

Para realizar el análisis primeramente se realiza la transcripción de las entrevistas y se cotejan con los informantes, considerando el proceso de análisis como un proceso cíclico y una actividad reflexiva, donde el proceso analítico debe ser amplio y sistemático pero no rígido, y donde la fragmentación de los datos y la división de los mismos en unidades significativas mantiene una unión con el total. (Coffey \& Atkinson, 2003).

\section{RESULTADOS}

Las PVVS aducen haber utilizado los recursos vegetales, argumentando recurrir a ellos porque desde su perspectiva se sienten bien cuando los consumen, consideran que mejora su estado de salud o previenen algunas enfermedades, además de que esto forma parte de sus costumbres y cultura. Cabe señalar que no por sus valores culturales dejan de acudir a la Medicina Científica u Oficial ya que las personas entrevistadas hacen uso de ambas medicinas realizando una combinación de ellas utilizando los recursos naturales según su necesidad desde su perspectiva.

Se lograron identificar 39 diferentes recursos vegetales como plantas medicinales, frutos y verduras, usados como alternativa o complemento de tratamiento por los PVVS para prevenir o tratar diferentes tipos de padecimientos, no fueron mencionados en especifico algunos recursos minerales o animales para el tratamiento ya que se inclinan más hacia las plantas medicinales, los sujetos argumentaron consumirlos porque con ellos se sienten mejor en su estado general y que disminuyen el decaimiento, las nauseas y el vómito.

Los recursos naturales los adquieren en la localidad en algunos expendios como hierbearías o tiendas naturistas así como en sus propios jardines y se los recomiendan personas del grupo socialfamiliar y del grupo de autoapoyo al cual pertenecen. Responden que su familia específicamente la Mamá, acostumbra algunas prácticas tradicionales de salud realizándola con la misma familia, y que vecinos y amigos les han recomendado diversos recursos terapéuticos naturales para tratar las enfermedad oportunistas o algún malestar que se les presenta. (VER CUADRO)

Los médicos participantes emitieron sus opiniones en donde consideran que el uso de los recursos naturales como alternativa o complemento de tratamiento en el VIH, no es científico y con sus respuestas concretas refieren desconocer de plantas medicinales o medicina alternativa.

\section{DISCUSIÓN}

En el presente estudio se plantearon 3 objetivos generales y 2 específicos para determinar cuáles son los recursos naturales utilizados como tratamiento alternativo o complementario por las PVVS que acuden a un grupo de autoapoyo y la efectividad desde su perspectiva, en Tampico Tamaulipas, México, y un tercer objetivo que per- 


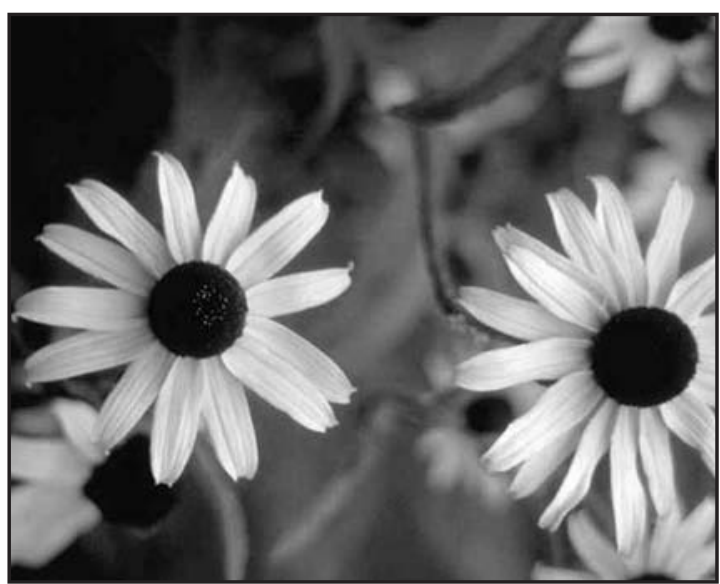

mitió indagar la opinión de los médicos con relación a este tema. La muestra recayó en 14 informantes (PVVS) con los cuales se realizaron entrevistas conversacionales incidentales y 4 entrevistas a profundidad, habiéndose elegido dos de estas últimas como informantes clave.

Los resultados arrojados señalan que los PVVS de Tampico, pertenecientes al grupo conocen y hacen uso de la medicina complementaria o Alternativa de acuerdo a su perspectiva, evidenciado a través de 39 recursos naturales en su totalidad vegetales entre los que se encuentra $64 \%$ (25) a plantas medicinales, el 23\% (9) a frutos y $13 \%$ (5) a verduras. Utilizándola para resolver 39 afecciones de las cuales $18 \%$ (7) son para purificar la sangra según lo refieren, $15 \%$ (6) para prevenir o tratar la diarrea, $20.5 \%$ (8) sumando las que usan para la gripa, tos y garganta, el resto de los recursos mencionados a porcentajes menores al $4 \%$ para cada una, siendo en un 5\% (2\%) las señaladas para SIDA.

Confirmándolo con lo que señala el líder del grupo de autoapoyo, quien refiere que la mayoría de las personas del grupo utilizan algún recurso alternativo o complementario, indistintamente de que lleven un tratamiento antirretroviral o no, estos han sido recursos vegetales, yoga, temazcal, siendo este último una alternativa o complemento que no se ha encontrado reportada en los estudios revisados hasta el momento. (ANEXO: No. 12 y 13)

Es evidente que en este grupo la cultura está presente en sus costumbres y creencias de salud, que determinan el uso de los recursos naturales como tratamiento alternativo o complementario en el VIH/SIDA, ya que en ellos persiste la cultura de la Medicina Tradicional derivada de sus valores y las formas de vida del entorno social al que pertenecen, que les permite tener su propia cosmovisión y favorecer esta acción, confirmándose así el supuesto de estudio.

Es de relevancia destacar que los resultados coinciden totalmente o quizá superan a lo señalado por la OMS en 1984, que confirma este hecho reportando que entre el 70 y $90 \%$ de las enfermedades no son tratadas solo por los sistemas convencionales de salud. (OMS). Además de lo referido en un estudio reciente, que demuestra que el $78 \%$ de los pacientes que padecen de VIH/SIDA en EE.UU., utilizan alguna forma de medicina tradicional o complementaria alternativa, para obtener cura sintomática y tratar las infecciones oportunistas. También señala que en los países en vías de desarrollo hasta el $80 \%$ de su población utiliza la herbolaria alguna otra alternativa. (OMS 2002 al 2005).

De igual forma Oramas y Rodríguez (1999), refieren que en Australia el 80\% de las personas infectadas por el VIH han recurrido a alguna forma de tratamiento alternativo empleando aceites esenciales, hierbas aromáticas y extractos de flores, haciendo referencia de que los productos empleados con el objeto de mejorar los males que aquejan al hombre, lo han acompañado en el transcurso de los siglos, señalado en esto también por Lagarriga (1975, 1999) y Piñones (1992).

En el documento sobre estrategias de la medicina tradicional 2002 al 2005 de la OMS, hace referencia que la atención en África subsahariana, la mayoría de los africanos que viven con el VIH/SIDA utilizan medicinas tradicionales con base de hierbas para obtener una cura sintomática. Considerando el listado de recursos vegetales que nos reportan los PVVS de Tampico, nos indica como en ellos persiste la cultura del uso de la medicina tradicional a través de los recursos naturales, influenciada por su cosmovisión.

Los resultados del presente trabajo supera a lo argumentado por la OMS (2002) y Oramas (1999), que señalan que el $80 \%$ de las PVVS hacen uso del la medicina complementaria o alternativa, demostrando con ello la importancia de tomar en cuenta las diferentes culturas y convicciones de salud y la enfermedad, así como los modelos de conducta de 
los individuos, con el propósito de llevar a cabo una práctica de atención de enfermería específica de la cultura como lo señala Leininger.

Asi mismo ella centra en el análisis de su estudio que los patrones y estilos de vida, tienen influencia en las decisiones de las personas, esta teoría ayuda a la enfermera a descubrir y documentar el mundo del paciente y utilizando su punto de vista émico. (Leininger en enfermería 21.com 2003).

También Piñones (1992) señala la importancia de que la Medicina Tradicional actualmente esté resurgiendo paralela al uso de la medicina científica y que esto puede estar ligada a las condiciones sociales y económicas. Argumenta que el uso de la herbolaria presenta una respuesta social y cultural que la comunidad hace ante la realidad de su problemática de salud y que independientemente de que esta cuente con servicios oficiales de salud, continúan con el uso de la Medicina Tradicional, siendo esta la primera alternativa que elige al ver afectada su salud con los primeros síntomas de cualquier tipo de enfermedad.

Con respecto a la opinión de los médicos sobre el que las PVVS utilicen recursos naturales como alternativa o complemento en el tratamiento del VIH/SIDA, el 60\% (8 médicos) están de acuerdo con su uso y el $40 \%$ no lo aceptan. Esto hace evidente el desconocimiento de lo señalado por la $56^{\mathrm{a}}$ asamblea de salud en marzo del 2003, donde se hace mención de la importancia que el uso de la medicina tradicional tiene en las enfermedades cónicas, para mejorar la calidad de vida, incluyendo la enfermedad del VIH/SIDA.

Así también no se retoman las estrategias y recomendaciones de la OMS para 2002 al 2005, donde se considera que los patrones de creencias y el uso de la medicina tradicional y el uso de la herbolaria es parte integral e importante en la vida de las personas, haciendo énfasis al mencionar que Un elemento relevante a tener en cuenta en este campo lo constituye el riesgo de interacciones medicamentosas y que ha sido demostrado que algunos fitofármacos modifican las concentraciones plasmáticas y el efecto de drogas antirretrovirales como por ejemplo Hypericum Perforatum disminuye las concentraciones de Indinavir entre un $20 \%$ y $50 \%$; Lentinus edodes incrementa la acción de las drogas retrovirales.
Es importante mencionar que los resultados obtenidos del personal médico en este estudio tampoco concuerdan con lo señalado por Taddei y Santillana (1999), ya que ellos en un trabajo cuantitativo de "Aceptación y uso de la herbolaria en medicina familiar" en la CD. De Hermosillo Sonora, México, obtuvieron que el $83 \%$ de los médicos aceptan la herbolaria y que además el $75 \%$ de ellos reconocen hacer uso de ella.

En menor medida se acerca con lo señalado por Lagarriga (1999), Rachel King(2002), Quedrago (2003), y ni con la UNESCO( 2004), pues todos ellos mencionan lo relevante del respeto a la diversidad cultural con el propósito de desarrollar una base de conocimientos científicos y humanísticos que permitan una práctica de atención sanitaria especifica de la cultura y/o universal como lo señala Leininger.

\section{CONCLUSIONES}

Con base a testimonios es evidente que en este grupo la cultura está presente en sus costumbres y creencias de salud, que determinan el uso de los recursos naturales en el VIH/SIDA, ya que en ellos persiste la cultura de la Medicina Tradicional derivada de sus valores y la forma de vida del entorno social al que pertenecen, que les permite tener su propia cosmovisión favoreciendo esta acción. La cosmovisión del individuo es determinante para la salud, nutrida por la cultura como base fundamental de sus costumbres, creencias y tradiciones, que en conjunto con la experiencia previa del grupo social que les rodea, determina el concepto de salud-enfermedad desde su perspectiva.

Leininger con su modelo de enfermería transcultural, nos sugiere que se deben considerar las diferentes culturas respecto a las convicciones de la salud y la enfermedad, que permita una práctica de la atención sanitaria específica, ya que los patrones y estilos de vida tienen influencia en las decisiones de las personas, además considera de gran importancia los punto de vista émicos, la esencia interna del ser, y sugiere que al combinar estos con el conocimiento profesional, se podrán adoptar acciones y decisiones coherentes a la cosmovisión. 


\section{BIBLIOGRAFÍA}

- Aguirre .B. (1986). Antropología médica. Centro de investigación y estudios superiores en antropología social. México:

- Chelala, C. A. (1993) SIDA Organización Panamericana de la Salud, Programa de Publicaciones OPS.

- Daniel, S.G, V. (1989). SIDA Síndrome de Inmunodeficiencia Adquirida, Editorial Manual Moderno, México, D.F.

- Estrada, L.(1991 Compilador) Plantas medicinales de México. Introducción a su estudio. Universidad Autónoma de Chapingo, Departamento de Fitotecnia, Unidad de estudios Etnobotánicos. México.

- Foster, M. (1961) Análisis Antropológico-Intercultural de un programa de ayuda técnica, Washington, Smithsonian Institute.

- Guía de manejo Antirretroviral de Personas que viven con el VIH/SIDA (2003 -2004) Consejo Nacional para la Prevención y control del VIH/SIDA (CENSIDA). www.salud.gob.mx/ conasida

- Kelly, Isabel (1959) La Antropología , la Cultura y la Salud Pública. La Paz Bolivia, VSOM-Bolivia.

- Koos,J.D. (1992 cap-10, p-154-165) La Etnomedicina en la Salud Mental en la Comunidad. Temas de Salud Mental en la comunidad serie PALTEX Para ejecutores de programas de Salud no. 19 Washington D.C. E.U.A.

- Kumate, R.(1990,noviembre -diciembre p.9,5, 17,22) Libellus de Medicinalibus Indorum Herbis. Ciencia y Desarrollo. México.

- Lagarringa, Attias I. (1999) Las enfermedades tradicionales regionales en la medicina tradicional en el norte de México. Colección Científica. INAH. Lagarringa, Attias, I. (2000) Conceptos, actitudes y valores de sus seguidores. En Medicina Tradicional en México. Instituto Nacional de Enfermedades respiratorias (INER) México.

- Linares, M., Flores, P. y Bye, R.(1990) Selección de Plantas Medicinales de México. Limusa Noriega. México.

- Lozoya, X. (1984) Bibliografía básica sobre herbolaria medicinal de México. Secretaria de Desarrollo Urbano y Ecología. México.

- Lozoya, X., Velásquez, G. (1988) La medicina tradicional en México.

- Experiencias del panorama IMSS-COPLAMAR 1989 - 1987. IMSS (P. 9-4, 38-39)

- Marriner (1994 3 $3^{\mathrm{a}}$ Ed.) Modelos y teorías de enfermería. Harcourt Brace, S. A. (p. 424 - 445)

- Martínez Maximino. (1991 6 Ed.) Las plantas Medicinales de México. Ediciones Botas. México.

- Menéndez, E.(1983) Hacia una práctica alternativa hegemónica y auto atención (gestión) en salud. Centro de Investigación y estudios superiores en Antropología Social (CIESAS), México.

- Menéndez, E. (1987) Medicina tradicional o sistemas prácticos ideológicos de los conjuntos sociales, como primer nivel en atención. En el futuro de la medicina tradicional en la atención ala salud de los países Latinoamericanos, México CIESS. - OMS Estrategias sobre medicina tradicional 2002 al 2005.

- Ortiz E. S. (1999) La Medicina Tradicional al Norte de México. Colección científica. INAH, México.

- Piñones, M. S. (1992) Persistencia de la medicina tradicional en familias de una comunidad urbana-marginada, Pueblo Nuevo, Apodaca, N.L. Tesis de maestría en Enfermería con especialidad en salud comunitaria, énfasis en familia. México.
(Inédita: Biblioteca Facultad de Enfermería Tampico, UAT México) (2000 Septiembre) Medicina tradicional en el Noreste

- De México "Etnoenfermeria", memorias de Houston International Community Health Summit, Inc. Houston Texas. (p. 187)

- Peñarrieta, C. I.; Piñones, M .S. (14 -15 de Abril 2005) Análisis situacional del VIH/SIDA en la frontera de Tamaulipas, México. Informe inédito Grupo Multisectorial Binacional. The Policy Project., Reunion Binacional Tamaulipas -Texas.

- Salinas Cantu, H. (1991) Historias y Filosofía Medica. Monterrey N. L. (4ª Ed.) México.

- Siles, J.; et al. (2001) Una mirada a la situación científica de dos especialidades esenciales de la Enfermería contemporánea: la antropología de los cuidados y la enfermería transcultural. Cultura de los Cuidados. V/10 64-72.

- Siles González, J., Solano Ruiz, C., Cibanal Juan, L. (2005) Holismo e investigación cualitativa en el marco de la antropología de la complejidad. Una reflexión sobre la pertinencia metodológica en ciencias socio-sanitarias y humanas. Cultura de los cuidados. IX/18: 68-83.

- Taddei, G; Santillana, M.A.; Romero, J:A.; Romero, M:B; (Mayo/junio 1999). Aceptación y uso de Herbolaria en Medicina Familiar. Salud Pública de México, Vol.41 No.3 Cuernavaca Morelos, México. Print ISSN 0036-3634.

- UNESCO.(2008) Recomendaciones de la UNESCO sobre la terminología y la redacción del material relativo al VIH y al SIDA.

- Zolla, C. (1986) Terapeutas, Enfermedades y Recursos Vegetales.

- México Indígena. (marzo-abril, p.9, 16-19) México.

\section{Direcciones electrónicas:}

- BMJ 1997; 315: 1689-1691, Primer caso de SIDA http://www.bmj.com

- Consejo Nacional Para la Prevención y el Control del SIDA en México (CONASIDA -2005) http://www.salud.gob.mx/conasida/2005

- Erick Estrada Lugo. Coordinador del programa de Medicina Tradicional en la Universidad Autónoma de Chapingo.http://www.jornada.unam.mx/1998/06/29/ cienpanorama.html consultada agosto 2006.

- Herbolariamedicinal o fitoterapia http://www.e-salud.gob.mx/ wb2/eMex/eMex_Fitoterapi

- Información VIH/SIDA, estadística del Estado de Florida http://www.wemakethechange.com/about_hir-aids-sp.html

- Información VIH/SIDA estadística en Tamaulipas.

- HTTP://WWW.salud.gob.m/conasida/estadis/2002/trim3/0203-02.HTML

- La Medicina Complementaria Alternativa (MCA), la medicina China y la enfermedad VIH, Boletín publicado en octubre de 1997 en el Boletín de Tratamientos Experimentales Contra el SIDA, por la Fundación anti-SIDA de San Francisco. http://www.sfaf.org/tratamiento/betaespanol/s1097/index.htm/ - Los Recursos Naturales (definición) http://www.peruecologico.com.pe/lib_c15_t05.htm

- Marco Legal, Ley General de Salud se reconoce desde el 7 de mayo de 1997 http://www.farmacopea.org.mx/

- Medicina alternativa http://www.nlm.nih.gov/medlineplus/ spanish/alternativemedicine.html 
- Medicina alternativa en SIDA. http://www.todosida.org /info/hierbas.htm

- Medicina alopática, complementaria y alternativa http://www.adusalud.org.ar/vihsida.htm Argentina.

- Medicina herbal: tratamiento alternativo para el SIDA, http://www.ciudadfutura.com/

- Medicinas, hierbas, y suplementos. http://medlineplus.gov/ spanish/

- Oramas, D. J., y Rodríguez, L.I , Resumen 1999;12 (1): p-3946, Artículo la información científica y la medicina tradicional y natural.

- Organización Mundial De La Salud 56 a Asamblea Mundial De La Salud A56/18 Punto 14.10 Del Orden Del Día Provisional 31 De Marzo De 2003. Medicina Tradicional Informe De La Secretaría. http://www.who.int/gb/ebwha/pdf_files/WHA56/ sa5618.pdf

- Perspectivas políticas sobre medicamentos de la OMS, Medicina Tradicional -Necesidades Crecientes y Potencial, No. 2 - Mayo de 2002 Organización Mundial de la Salud, Ginebra.www.masaje.info/trm_strat_span.pdf

- Portal Tampico 2005: http://www.tampico.gob.mx/tampico1/ tampico.asp

- Primer caso de Sida en México. Leopoldo Nieto Cisneros, Participantes en el trabajo sobre VIH/SIDA en México. http://www.aids-sida.org/participnal_n.html
- Quédrago, T. Alfred. Experiencia de un enfermero con la Medicina Tradicional. Index Enferm 2003; 43:8. Disponible en: <http://www.index-f.com/index-enfermeria/43revista/43_ articulo_8.php>.

- ¿Qué es la medicina complementaria y alternativa? http://nccam.nih.gov/espanol/informaciongeneral/

- ¿Qué Son Las Terapias Alternativas? http://www.aidsinfonet.org/index.php

- Rachel king. Colaboración con curanderos tradicionales en la prevención y atención de VIH/SIDA en el África subsahariana. Programa conjunto de las naciones unidas sobre el VIH/SIDA (ONUSIDA). (junio de 2002). Colección mejores prácticas de ONUSIDA. Ginebra. Resumen del sida, núm. 8 (publicado: 2002.10), pág. 6.

- Secretaria de Salud, Subsecretaría de Innovación y Calidad, Dirección General de Planeación y Desarrollo en Salud, Dirección de Medicina Tradicional Desarrollo Intercultural. Cultura, Cosmovisión y Sistemas Médicos. (2000-2006) http://www.ssa.gob.mx

- Tamaulipas existían 21 casos VIH registrados en la secretaria de salud en el año 2001 (CONASIDA) salud.gob.m/conasida/estadis/2002/TRIM-3/0203-02.html

- Teoría transcultural de Leininger. Manrique, M., Reyes, I, Delgado, H., I, Jiménez, B. http://www.enfermería21.com/listametas/Leininger_monografía.doc, Valencia. Junio 2003 Universidad de Carabobo.

\section{CUADRO}

Recursos vegetales utilizados por las PVVS. Como tratamiento alternativo o complementario en el VIH/SIDA.

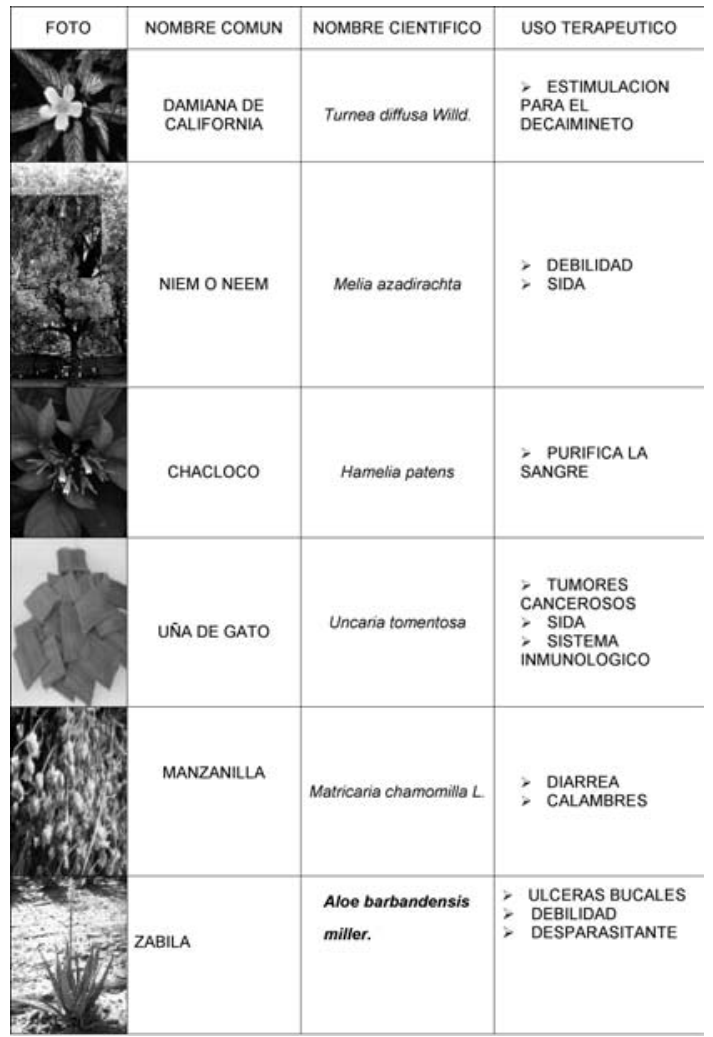

